\title{
Inhibition of the Casein-Kinase-I-Epsilon/Delta Prevents Relapse-Like Alcohol Drinking
}

\author{
Stéphanie Perreau-Lenz ${ }^{*}, 1,4$, Valentina Vengeliene ${ }^{1,4}$, Hamid R Noori', Emilio V Merlo-Pich ${ }^{2}$, \\ Mauro A Corsi ${ }^{3}$, Corrado Corti*,3 and Rainer Spanagel ${ }^{1}$ \\ 'Institute of Psychopharmacology, Central Institute of Mental Health, Medical Faculty Mannheim/Heidelberg University, Mannheim, Germany; \\ ${ }^{2}$ Hoffmann-LaRoche, Basel, Switzerland; ${ }^{3}$ Aptuit, Medicine Research Centre, Verona, Italy
}

\begin{abstract}
During the past decade, it has been shown that circadian clock genes have more than a simple circadian time-keeping role. Clock genes also modulate motivational processes and have been implicated in the development of psychiatric disorders such as drug addiction. Recent studies indicate that casein-kinase $\mid \varepsilon / \delta(\mathrm{CK} \mid \varepsilon / \delta)$ —one of the components of the circadian molecular clockwork-might be involved in the etiology of addictive behavior. The present study was initiated to study the specific role of CKI $\varepsilon / \delta$ in alcohol relapse-like drinking using the 'Alcohol Deprivation Effect' model. The effect of $C K \mid \varepsilon / \delta$ inhibition was tested on alcohol consumption in long-term alcohol-drinking rats upon re-exposure to alcohol after deprivation using a four-bottle free-choice paradigm with water, 5\%, $10 \%$, and $20 \%$ ethanol solutions, as well as on saccharin preference in alcohol-naive rats. The inhibition of CKI $\varepsilon / \delta$ with systemic PF-670462 (0, 10 , and $30 \mathrm{mg} / \mathrm{kg}$ ) injections dose-dependently decreased, and at a higher dosage prevented the alcohol deprivation effect, as compared with vehicle-treated rats. The impact of the treatment was further characterized using nonlinear regression analyses on the daily profiles of drinking and locomotor activity. We reveal that CKI $\varepsilon / \delta$ inhibition blunted the high daytime alcohol intake typically observed upon alcohol re-exposure, and induced a phase shift of locomotor activity toward daytime. Only the highest dose of PF-670462 shifted the saccharin intake daily rhythm toward daytime during treatment, and decreased saccharin preference after treatment. Our data suggest that CKI inhibitors may be candidates for drug treatment development for alcoholism.
\end{abstract}

Neuropsychopharmacology (2012) 37, 2 I2I-2I31; doi:I0.1038/npp.2012.62; published online 2 May 2012

Keywords: clock genes; casein kinases; alcohol addiction; relapse; biological rhythms; rats

\section{INTRODUCTION}

During the past decade, new unexpected players have emerged in the addiction field: clock genes. Several of these circadian time-keeping genes (Ko and Takahashi, 2006) have been shown to play a crucial role in the development of psychiatric disorders such as drug abuse (Falcon and McClung, 2009; Perreau-Lenz and Spanagel, 2008). For example, Period1 (Per1) and Period2 (Per2) have been shown to modulate various alcohol effects. Per1-null mutant mice show enhanced alcohol consumption under stressful conditions as compared with wild-type littermates (Dong et al, 2011). Per2 ${ }^{B r a m 1}$ mutant mice, expressing a nonfunctional PER2 protein, show an enhanced consumption of

\footnotetext{
*Correspondence: Dr S Perreau-Lenz, Institute of Psychopharmacology, Central Institute of Mental Health, J 5, 68159 Mannheim, Germany, Tel: + 49 (0) 621170362666, Fax: + 49 (0) 621 I7036255, E-mail: stephanie.perreau-lenz@zi-mannheim.de or Dr Corrado Corti, Aptuit, Medicine Research Centre, via Alessandro Fleming 4, 37I29 Verona, Italy, Tel: + 390458219 576, Fax: + 390458218047 , E-mail: corrado.corti@aptuit.com

${ }^{4}$ These authors contributed equally to this work.

Received 6 September 2011; revised 2 April 2012; accepted 2 April 2012
}

alcohol (Spanagel et al, 2005; Brager et al, 2011), as well as a deregulation of the daily rhythm of alcohol sensitivity (Perreau-Lenz et al, 2009). The effects of alcohol on clock genes and biological rhythms have also been observed. In rodents, acute or long-term alcohol administration can affect circadian locomotor activity (Brager et al, 2010; Rosenwasser et al, 2005b). In humans, Huang et al (2010) recently demonstrated that in peripheral blood mononuclear cells, the expression of several clock genes, including Per genes, is lower in alcoholic patients as compared with healthy controls. These studies provide evidence of a reciprocal interaction between biological rhythms and alcohol addiction.

The circadian molecular clock system involves several transcriptional, posttranscriptional, and posttranslational feedback mechanisms (Ko and Takahashi, 2006). Among posttranslational regulators, casein-kinase $1 \varepsilon / \delta(\mathrm{CK} 1 \varepsilon / \delta)$, which belongs to the superfamily of serine/threoninespecific kinases, plays a major role in sustaining the circadian molecular clock. CK1 $\varepsilon / \delta$ phosphorylates several clock gene proteins, such as BMAL1, CRY, PER1, and PER2 (Eide et al, 2005a, b; Meng et al, 2008), sustaining their heterodimerization, entry in the nucleus, and/or destabilization in a circadian manner (Reischl and Kramer, 2011). 
The rhythmic destabilization of the PER2 protein is fully regulated by $\mathrm{CK} 1 \varepsilon / \delta$ phosphorylation processes (Eide et al, 2005b; Etchegaray et al, 2009; Meng et al, 2008). Indeed, the tau mutation of the CK1 $\varepsilon$, a gain-of-function mutation, promotes PER2 degradation, thereby accelerating circadian activity (Meng et al, 2008). Furthermore, both inducible genetic deletion of CK1 $\delta$ enzymes (Etchegaray et al, 2009, 2010) and $\mathrm{CK} 1 \varepsilon / \delta$ pharmacological inhibition (Badura et al, 2007) induce phase delays of locomotor activity and enhance PER2 protein levels.

Interestingly, recent human genetic association studies suggest a role for $\mathrm{CK} 1 \varepsilon / \delta$ in the development of addiction to several drugs of abuse, such as metamphetamine (Kotaka et al, 2008), heroin (Levran et al, 2008), and alcohol (Al-Housseini et al, 2008). Furthermore, CK1 $1 \delta / \delta$ has also been associated with the locomotor stimulant effect of methamphetamine in mice (Bryant et al, 2009). Bryant et al (2009) first showed that $\mathrm{CK} 1 \varepsilon / \delta$ inhibition blunted the locomotor stimulant effects of methamphetamine and revealed a stimulatory effect of the selective CK1\& subunit on the sensitivity to methamphetamine and fentanyl (Bryant et al, 2012).

Considering these recent studies on $\mathrm{CK} 1 \varepsilon / \delta$ and the role of clock genes in modulating alcohol consumption, we hypothesized that $\mathrm{CK} 1 \varepsilon / \delta$ might play a role in alcohol addiction. Because alcohol relapse is a major impediment to the treatment of alcoholism, the present study was designed to study the role of the $\mathrm{CK} 1 \varepsilon / \delta$ in alcohol relapse behavior. In animals given long-term access to alcohol followed by deprivation of varying durations, re-exposure to alcohol leads to a robust and temporary increase in alcohol intake as compared with baseline drinking - the alcohol deprivation effect (Salimov and Salimova, 1993; Sinclair and Senter, 1968). This model (Spanagel and Hölter, 1999; Vengeliene et al, 2009) specifically assesses relapse-like drinking behavior and provides good predictive validity and, as such, has been used repeatedly to identify new putative antirelapse compounds (Spanagel, 2009; Spanagel and Kiefer, 2008). We therefore tested the effects of $\mathrm{CK} 1 \varepsilon / \delta$ inhibition - using the previously characterized compound PF-670462 (Meng et al, 2010) - on alcohol relapse-like drinking by means of the alcohol deprivation effect model in long-term alcohol-drinking rats. We further analyzed the daily patterns of drinking and locomotor activity data before, during, and after drug treatment. Furthermore, we further assessed the effects of $\mathrm{CK} 1 \varepsilon / \delta$ inhibition on consumption of another rewarding solution, saccharin.

\section{MATERIALS AND METHODS}

\section{Animals}

Two-month old male Wistar rats (originating from our breeding colony at the CIMH, Mannheim, Germany) were housed individually in standard rat cages (Ehret, Emmendingen, Germany) and kept under a $12 \mathrm{~h}$ light/dark cycle (lights on at $0800 \mathrm{~h})$ with constant temperature $\left(22 \pm 1{ }^{\circ} \mathrm{C}\right)$ and humidity $(55 \pm 5 \%)$. Standard laboratory rat food (Ssniff, Soest, Germany) and tap water were provided ad libitum throughout the experiments. All experimental procedures were approved by the Committee on Animal Care and Use (Regierungspräsidium Karlsruhe) and carried out in accordance with the local Animal Welfare Act and the European Communities Council Directives (86/609/EEC).

\section{Drugs}

Alcohol and saccharin drinking solutions were prepared from 96\% ethanol (Merck, Darmstadt, Germany) and saccharin (Sigma Aldrich Chemie GmbH, Munich, Germany) diluted with tap water. The $\mathrm{CK} 1 \varepsilon / \delta$ inhibitor PF-670462 was synthesized by GSK (GlaxoSmithKline, Verona, Italy) based on previously developed and tested compounds (Badura et al, 2007; Etchegaray et al, 2009; Walton et al, 2009). PF-670462 (10 or $30 \mathrm{mg} / \mathrm{kg} ; 2 \mathrm{ml} / \mathrm{kg}$ ) was dissolved in the following vehicle: $12.5 \%$ SBE7- $\beta-C D$ Captisol (CyDex, Lenexa, KS) and $25 \mathrm{mM}$ citrate buffer (pH 6.0) in milliQ water. All solutions were prepared immediately before each injection. Drug doses were chosen on the basis of previously published studies (Badura et al, 2007; Etchegaray et al, 2010; Meng et al, 2010; Walton et al, 2009) and our pilot experiments (unpublished observations).

\section{Drinking Measurements by the Drinkometer System}

Drinking patterns were assessed using a fully automated 'drinkometer' (custom-modified version from TSE, Bad Homburg, Germany) system combined with simultaneous homecage activity monitoring (Mouse-E-Motion by Infrae-motion, Henstedt-Ulzburg, Germany). Our drinkometer system (Vengeliene et al, 2012) enables continuous longterm monitoring of liquid consumption by amount and time. The system is equipped with four drinking stations, monitored by a computer, enabling a choice of up to four drinking solutions (ie, tap water, $5 \%, 10 \%$, and $20 \%$ ethanol solutions $(\mathrm{v} / \mathrm{v})$ or tap water in our alcohol-relapse experiment and saccharin in our second experiment). Each drinking station consists of a glass vessel and a highprecision sensor, providing ultra-high resolution-down to $0.01 \mathrm{~g}$. The weight of the vessel is measured in $200 \mathrm{~ms}$ steps. For the present study, sampling was performed at $10-\mathrm{min}$ intervals.

\section{Homecage Locomotor Activity Measurements by the E-Motion System}

Homecage locomotor activity was monitored using an infrared sensor device (Mouse-E-Motion by Infra-e-motion) placed $30 \mathrm{~cm}$ above each cage. Data were collected (every second, each $1.5 \mathrm{~cm}$ movement was detected and assigned a counting value) and processed with Microsoft Excel. Monitoring of locomotor activity was assessed during the past 6 consecutive baseline drinking days, as well as during 6 postabstinence drinking days for the alcohol experiment and during the 6 days after self-administration for the saccharin experiment.

\section{Pharmacological Studies}

Relapse-like alcohol drinking. All rats underwent a long-term alcohol-drinking procedure interrupted with repeated deprivation phases, as previously described (Vengeliene et al, $2005,2006,2007)$. Briefly, rats were given ad libitum access to tap water, $5 \%, 10 \%$, and $20 \%$ ethanol solutions (v/v). 
The positions of the bottles were changed weekly to avoid location preferences. The first 2-week deprivation period was introduced after 8 weeks of continuous alcohol availability. Rats were then given access to alcohol again. Alcohol access was further repeatedly interrupted in a random manner with 2- to 3-week deprivation periods in order to prevent adaptive behavioral mechanisms (Spanagel and Hölter, 1999). After the fourth deprivation period, all animals were transferred to the homecages of the drinkometer system.

Alcohol intake was monitored before and after the seventh deprivation period, and the pharmacological studies were initiated at the end of this deprivation period. Rats were divided into three groups of eight animals such that the mean baseline of total alcohol intake, calculated as $\mathrm{g} / \mathrm{kg} / \mathrm{day}$, was similar for each group. The experimental protocol, summarized in Supplementary Figure S1, was as follows: baseline drinking was monitored for 6 days. After the last day of baseline measurement, the alcohol bottles were removed from the cages, leaving the animals with free access to food and water for 25 days. Thereafter, each animal was subjected to a total of five intraperitoneal (i.p.) injections (starting at $1900 \mathrm{~h}$ with 12 -h intervals) of vehicle and 10 or $30 \mathrm{mg} / \mathrm{kg}$ PF-670462. The dose, schedule, and route of administration have been chosen based on several factors. First, the PF-670462 compound has been previously characterized in rats (Badura et al, 2007) and mice (Bryant et al, 2009). Despite the short half-life of the compoundshown by others and confirmed in our pharmacokinetic pilot study using one single i.p. injection of $30 \mathrm{mg} / \mathrm{kg}$ PF670462 (Cmax of $571 \mathrm{ng} / \mathrm{ml}$ at $0.5 \mathrm{~h}$ ) - the pharmacodynamics of the PF-670462 compound seem to be long lasting, as previously described by Badura et al (2007), who showed that circadian locomotor activity was affected for several days after a single injection of the compound. In addition, the schedule of five injections given $12 \mathrm{~h}$ apart was chosen to avoid stress effects induced by more frequent injections. Furthermore, numerous studies on the alcohol deprivation effect conducted in our long-term drinking rats with different compounds have demonstrated effectiveness in our model using the same treatment schedule (eg, Hölter and Spanagel, 1999; Hölter et al, 2000; Vengeliene et al, 2005, 2006, 2007, 2010). Alcohol bottles were reintroduced after the second injection at the onset of the light phase. Body weights were recorded $24 \mathrm{~h}$ before the first injection and $12 \mathrm{~h}$ after the last injection.

Saccharin consumption. Alcohol-naive rats had free access to both water and saccharin $(0.001 \%(\mathrm{w} / \mathrm{v}))$ solutions in two drinking stations of the drinkometer system during the entire course of the experiment. The concentration of saccharin was determined to be the highest concentration that allows significant preference for the saccharin solution and for which the rats presented a standard total liquid intake per day ( $\leqslant 10 \%$ of body weight/day). Saccharin intake was monitored 6 days before the pharmacological treatment (baseline conditions), 2 days during the treatment administration (treatment conditions), and during the following 4 days (posttreatment conditions). Rats were divided into three groups of 5-8 animals, such that the mean baseline of saccharin intake, calculated as $\mathrm{ml} / \mathrm{kg} / \mathrm{day}$, and the preference for saccharin solution (\%) were similar for each group. Animals were subjected to a total of five i.p. injections of vehicle $(n=8)$ and $10 \mathrm{mg} / \mathrm{kg}(n=6)$ or $30 \mathrm{mg} / \mathrm{kg}(n=5)$ of the $\mathrm{CK} 1 \varepsilon / \delta$ inhibitor PF-670462. Furthermore, food intake was measured daily and the body weights of rats were recorded $24 \mathrm{~h}$ before and $12 \mathrm{~h}$ after treatment.

\section{Statistical Analyses}

Total daily alcohol and water consumption, as well as saccharin preference, were analyzed with Statistica (StatSoft, Tulsa, OK) using a two-way analysis of variance (ANOVA) with repeated measures. Body weight data analysis was performed using a one-way ANOVA. Whenever significant differences were found, post-hoc StudentNewman-Keuls tests were performed. The level of significance was $p<0.05$.

In order to provide an optimal approximation of the group average daily rhythm of drinking and locomotor activity, we further analyzed the data collected using the drinkometer and E-motion systems with a biologically plausible nonlinear model $f(t, a)$ within the curve fitting toolbox of MATLAB (see Supplementary Materials and Methods). Based on discrete Fourier transformations, the analysis suggested modeling the data with nonlinear regression functions of $24 \mathrm{~h}$ periods such as sine waves: $f(t, a)=a_{1} \sin \left(a_{2} t+a_{3}\right)+$ L. Each parameter reflects a specific characteristic of the periodic functions. The amplitude from the mean, $\left[a_{1}\right]$, denotes the difference between the maximal and the mean level (L) of ethanol intake, locomotor activity, or saccharin intake, respectively. The period, $\left[\pi / a_{2}\right]$, describes the actual duration of the daily rhythms normalized to $24 \mathrm{~h}$. The parameter phase shift $\left(12 \mathrm{~h}-\mathrm{a}_{3} * 12 / \pi\right)$ represents the shifts $(\mathrm{h})$ of our sinusoidal curves when compared with the ones obtained from the baseline conditions. As these time-independent parameters completely characterize the average regression functions, we used one-way ANOVA (controlled by Holm-Bonferroni method) to compare them with respect to the measurement day and the dosage of the drug. The global level of significance was $\alpha<0.01$.

\section{RESULTS \\ Effects of CK1 $1 \varepsilon / \delta$ Inhibition on Relapse-Like Alcohol Drinking}

As shown in Figure 1a, the vehicle-treated group showed an increase in alcohol consumption following re-introduction of alcohol solutions, indicating the occurrence of an alcohol deprivation effect. This increase was similar to the ones observed after the first six deprivation phases (data not shown). In contrast, as compared with vehicle-treated rats, treatments with 10 and $30 \mathrm{mg} / \mathrm{kg}$ PF-670462 reduced and abolished, respectively, the alcohol deprivation effect. Furthermore, the higher dose significantly decreased alcohol intake below baseline levels for the 6 days after alcohol re-exposure. In order to maintain overall liquid intake and as previously observed (Vengeliene et al, 2006, 2007,2010 ), a compensatory decrease in the consumption of water occurred upon alcohol re-exposure in vehicletreated rats (Figure $1 \mathrm{~b}$ and Supplementary Figure S2). 

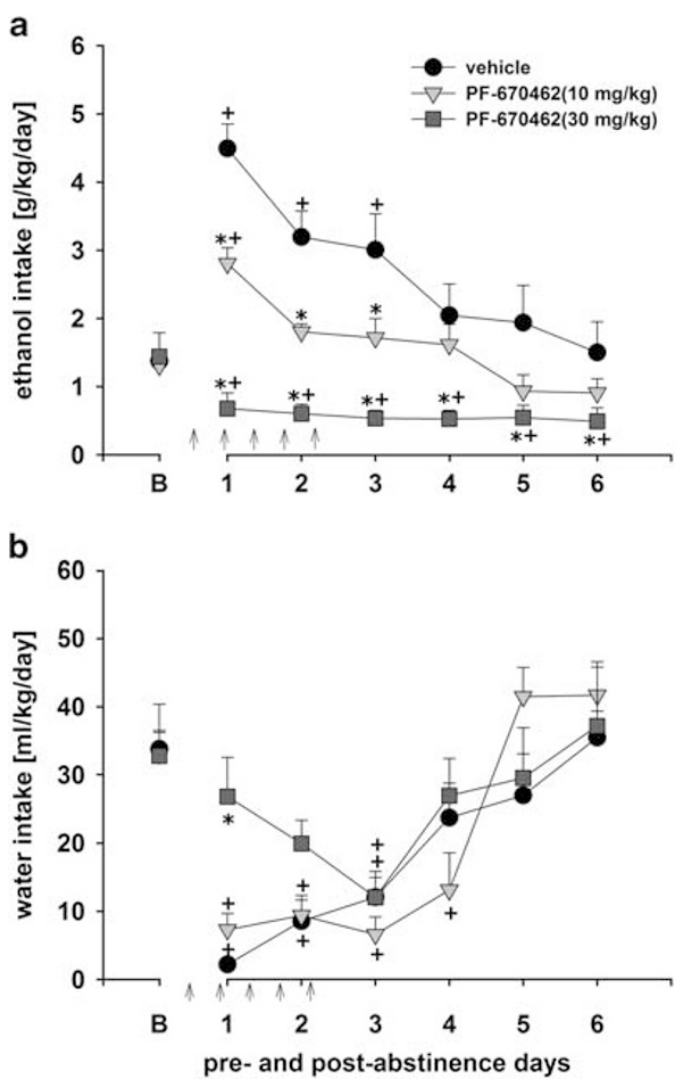

Figure I Total daily alcohol (a) and water (b) intake in vehicle- $(n=8)$, $10 \mathrm{mg} / \mathrm{kg}$ PF-670462- $(n=8)$, and $30 \mathrm{mg} / \mathrm{kg}$ PF-670462-treated $(n=8)$ animal groups. (a) Total daily intake is presented as the sum of all alcohol solution taken for a period of $24 \mathrm{~h}$. Baseline drinking (b) is calculated as the daily average intake across the last 6 measuring days. Alcohol intake was significantly affected by the re-introduction of alcohol solutions following the period of deprivation as compared with the baseline drinking intake $\left(F_{\text {Day }}(6, I 26)=27.4, p<0.000 I\right)$. However, although the vehicle-treated group showed a characteristic increase in alcohol consumption, the pharmacological treatments with 10 or $30 \mathrm{mg} / \mathrm{kg}$ PF-670462 caused a significant and dose-dependent $\left(F_{\text {Group }}(2,2 I)=13.2, p<0.00 I\right)$ reduction in alcohol intake during the postabstinence drinking phase $\left(F_{\text {Day }} \times \operatorname{Group}(12,126)=11.7, p<0.000 \mathrm{I}\right)$. (b) After the deprivation phase, daily water intake was affected in all groups as compared with baseline drinking $\left(F_{\text {Day }}(6,126)=32.4, p<0.000 \mathrm{I}\right)$. However, the treatment differentially affected water intake $\left(F_{\text {Day }} \times \operatorname{Group}(12,126)=3.6, \quad p<0.00 I\right)$ : vehicle- and $10 \mathrm{mg} / \mathrm{kg}$ PF-670462-treated rats decreased their consumption, whereas $30 \mathrm{mg} / \mathrm{kg}$ PF-670462-treated rats showed no change on the first day. From the fifth postabstinent day on, all animals had similar water consumption as in baseline conditions. Arrows indicate the administration of either vehicle or PF-670462. Data are presented as means + SEM; + and * indicate post-hoc significant difference $(p<0.05)$ from baseline drinking and control vehicle group, respectively.

In contrast, $30 \mathrm{mg} / \mathrm{kg}$ PF-670462-treated rats did not reduce their total water intake during the first postabstinence days.

Under baseline alcohol-drinking conditions (Figure 2a), we observed a clear $24 \mathrm{~h}$ pattern in alcohol intake in all three groups of rats. Similar periods of the curve fits were detected for vehicle- and 10-, and $30 \mathrm{mg} / \mathrm{kg}$ PF-670462treated animals (Table 1a and Supplementary Table S1A), and no significant difference was observed in any of the given equation parameters (Supplementary Table S1A).
During treatment (Figure $2 \mathrm{~b}$ and Table 1a), mean levels of intake were significantly $(\mathrm{F}(1,6)=65.61, p<0.0001)$ increased $(>3.75$-fold), and a significant phase shift $(\mathrm{F}(1,6)=28.83, p<0.0001)$ of $5.28 \mathrm{~h}$ was observed in vehicle-treated rats. During posttreatment days (Figure 2c), vehicle-treated rats nearly recovered their initial baseline intake pattern, despite a slight phase delay of $2.4 \mathrm{~h}$, as shown by the similar other equation parameters (Table 1a).

During treatment with 10 and $30 \mathrm{mg} / \mathrm{kg}$ PF-670462, significantly lower phase delays and lower levels of intake compared with vehicle-treated rats were observed (Table 1a). During posttreatment days, although the mean levels of alcohol intake returned to baseline levels, the fourfold decrease in amplitude from the mean and the $36.12 \mathrm{~h}$ period indicate a flattening of the drinking pattern after $10 \mathrm{mg} / \mathrm{kg}$ PF-670462 administration (Figure $2 \mathrm{c}$ and Table 1a). The $30 \mathrm{mg} / \mathrm{kg}$ dose blunted the daily rhythm of alcohol intake as revealed by the increased period of the fit $(48 \mathrm{~h})$ and the significant lower amplitude from the mean observed during and after the treatment. Moreover, mean levels of intake were significantly lower as compared with vehicle-treated rats (Table 1a). The disruption of the alcohol-drinking pattern by the administration of PF-670462 is further reflected in the negative correlation observed between the dose of the drug and the goodness of the nonlinear fits (Supplementary Tables S2 and S3).

Interestingly, when the rhythmic patterns of intake of each alcohol solution concentration were analyzed separately (Supplementary Figures S3-S5), we observed a pronounced difference in intake of the $20 \%$ solution (Supplementary Figure S5). Upon re-exposure to alcohol (Supplementary Figure S5B), the vehicle-treated rats showed a significant $(F(1,6)=42.29, p<0001)$ phase shift of their $20 \%$ alcohol-drinking pattern of $6 \mathrm{~h}$ toward the light phase, and a significant $(F(1,6)=15.65, p=0.001) 4.5$-fold increase of the mean levels of intake $(0.009$ to $0.04 \mathrm{~g} / \mathrm{kg}$ in baseline and treatment conditions, respectively). In contrast, the $20 \%$ alcohol intake of rats treated with 10 and $30 \mathrm{mg} / \mathrm{kg}$ PF-670462 was blunted.

Daily patterns of locomotor activity were affected by alcohol exposure, as shown by the dampened amplitude from the mean seen in vehicle-treated animals (Figure 3 and Table 1b). The mean levels of locomotion were not significantly reduced in PF-670462-treated rats as compared with vehicle-treated rats (Table $1 \mathrm{~b}$ and Supplementary Figure S7). However, in both PF-670462 treatment groups, the amplitude from the mean of the sinusoidal patterns of locomotion was reduced by twofold during the treatment phase. During the posttreatment days, the locomotor activity rhythm of $30 \mathrm{mg} / \mathrm{kg}$ PF-670462-treated rats was diminished and reversed ( $12 \mathrm{~h}$ phase shift) (Figure $3 \mathrm{c}$ and Table 1b).

Changes in body weights were differentially affected by the treatment $\left(\mathrm{F}_{\mathrm{Group}}(2,21)=130.4 ; p<0.0001\right)$. Vehicletreated rats showed a characteristic (see, eg, Vengeliene et al, 2005, 2006, 2007) $1.3 \pm 0.2 \%$ body weight increase. As compared with vehicle-treated rats, rats treated with $30 \mathrm{mg} / \mathrm{kg}$ PF-670462 showed a slight but significant decrease (post-hoc test: $p<0.0001$ ) of their body weight $(-0.6 \pm 0.2 \%)$, whereas rats treated with $10 \mathrm{mg} / \mathrm{kg}$ showed a significant (post-hoc test: $p<0.0001$ ) body weight increase $(4 \pm 0.2 \%)$. 
a

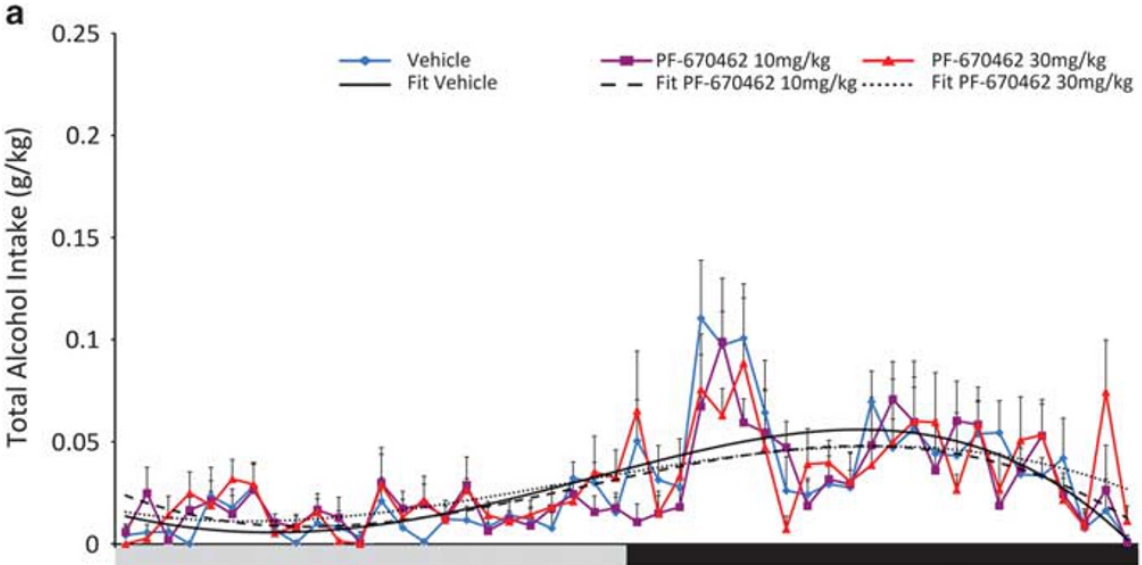

b

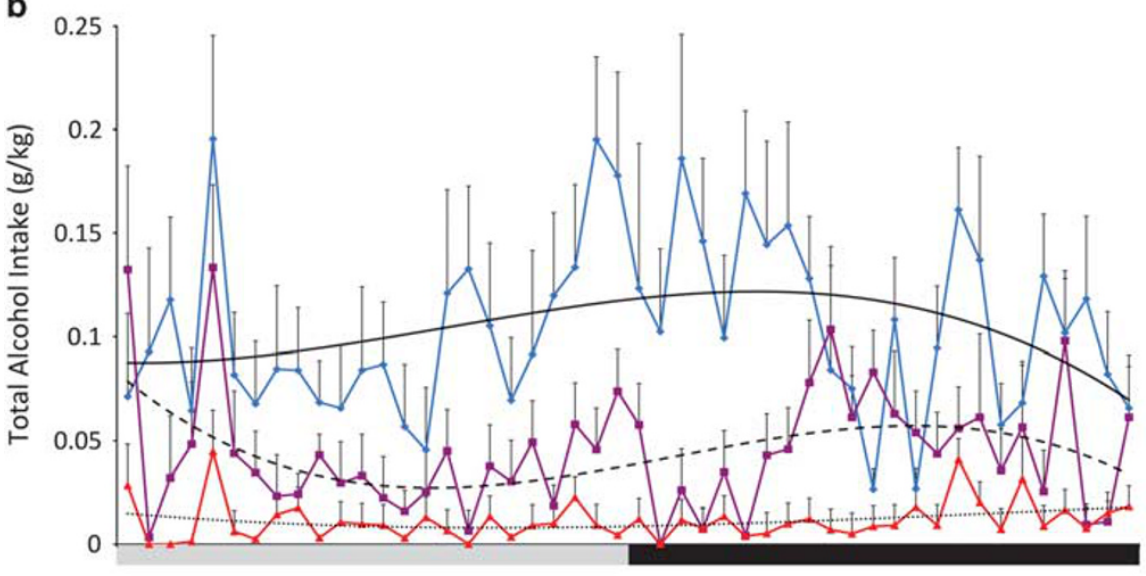

C

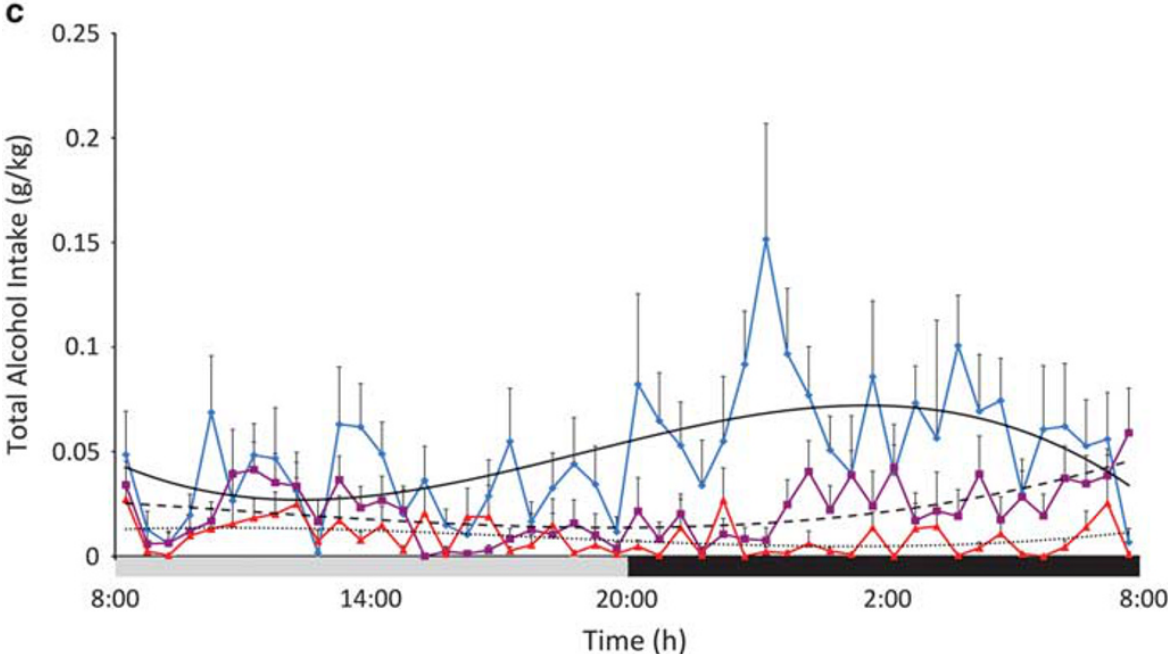

Figure 2 Curve fittings of daily rhythm alcohol drinking patterns under baseline conditions (a), during (b), and after (c) administration of vehicle and I0 and $30 \mathrm{mg} / \mathrm{kg}$ of PF-670462. Group-averaged total alcohol intake is presented as the sum of alcohol intake from all alcohol solutions taken every 30 min over a light/dark cycle for the last 6 baseline days (a), the 2 first days of alcohol re-exposure (b), and the 4 following days (c). During treatment and following reintroduction of the alcohol, alcohol intake significantly increased in vehicle-treated rats, especially during the light phase. During treatment with 10 and $30 \mathrm{mg} / \mathrm{kg}$ PF-670462, the shift in daytime drinking intake observed in vehicle-treated rats was less obvious and absent, respectively. Curve fits represent the best equation fit of our data. Data are presented as means + SEM.

\section{Effects of $\mathrm{CK} 1 \varepsilon / \delta$ Inhibition on Saccharin Consumption}

During treatment, no significant changes were observed on the daily preference for saccharin (Figure 4 and Supplementary Figure S6). However, a significant decrease of preference was observed in the $30 \mathrm{mg} / \mathrm{kg}$ PF-670462-treated rats as compared with the vehicle-treated rats during the posttreatment period. During this period, all $10 \mathrm{mg} / \mathrm{kg}$ PF-670462-treated rats demonstrated a $100 \%$ preference for the saccharin solution. 
Table I Custom Nonlinear Equations Parameters of the Regression Analysis Performed on Daily Patterns of Alcohol Drinking (a), Locomotor Activity (b), and Saccharin Intake (c) in Vehicle- and CKI $\& / \delta$ Inhibitor-Treated Groups of Rats

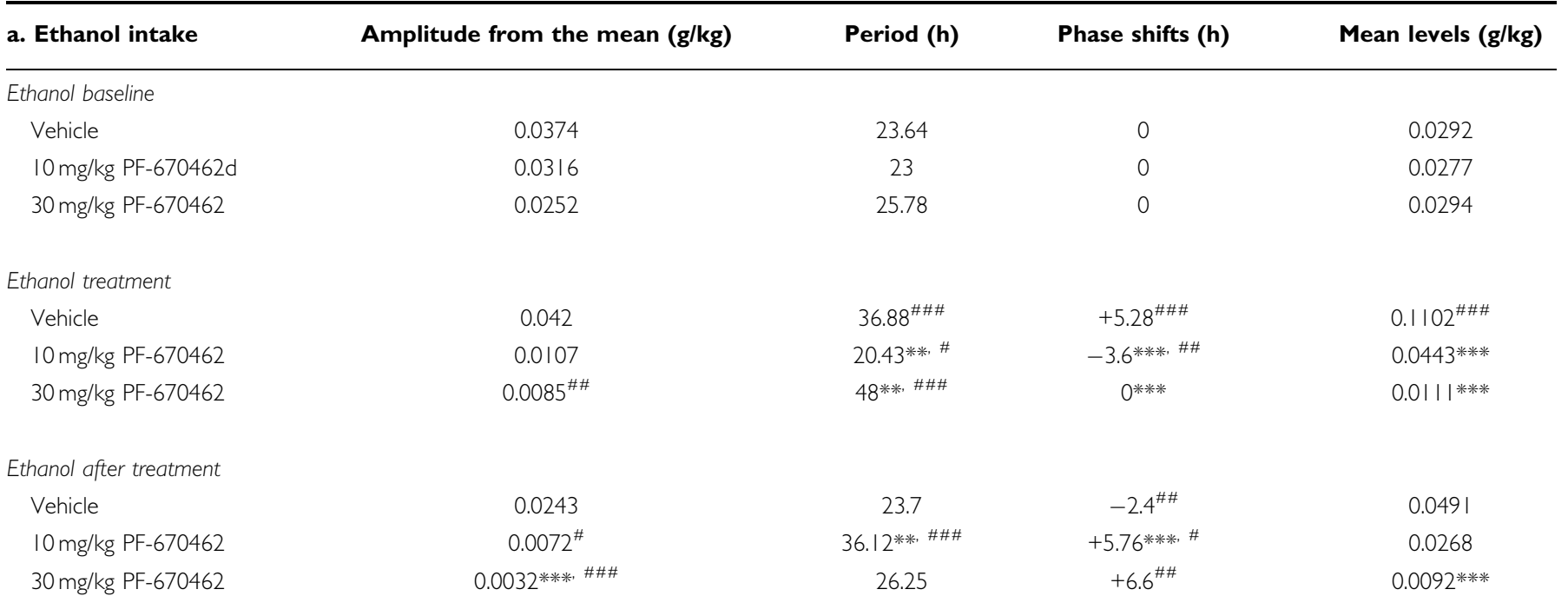

b. Locomotor activity

Activity baseline

Vehicle

10 mg/kg PF-670462

$30 \mathrm{mg} / \mathrm{kg}$ PF-670462

Activity treatment

Vehicle

10 mg/kg PF-670462

$30 \mathrm{mg} / \mathrm{kg}$ PF-670462

Activity after treatment

Vehicle

10 mg/kg PF-670462

$30 \mathrm{mg} / \mathrm{kg}$ PF-670462

c. Saccharin intake

Saccharin baseline

Vehicle

10 mg/kg PF-670462d

$30 \mathrm{mg} / \mathrm{kg}$ PF-670462

Saccharin treatment

Vehicle
$10 \mathrm{mg} / \mathrm{kg}$ PF-670462

$30 \mathrm{mg} / \mathrm{kg}$ PF-670462

Saccharin after treatment

$$
\begin{aligned}
& \text { Vehicle } \\
& 10 \mathrm{mg} / \mathrm{kg} \text { PF-670462 } \\
& 30 \mathrm{mg} / \mathrm{kg} \text { PF-670462 }
\end{aligned}
$$

Amplitude from the mean (counts)

Period (h)

Phase shifts (h)

Mean levels (counts)

27.48
26.53
27.1

25

21.63 *. \#

$20.4^{* * *}$

28.8

$30^{\#}$

16.8****

Amplitude from the mean $(\mathrm{ml} / \mathrm{kg})$

$$
\begin{aligned}
& 0.6325 \\
& 0.7495
\end{aligned}
$$

0.5176

0.4502

0.4811

0.2877
0.5478
0.5697

0.2877
0.5478
0.5697

24. 1

24.3

24.2
24. 1

23.6

24
0

0

0.9657

0.7012

0.8352

0.8242
0.7068

0.9299

$0.3359 * * * *$

Significant differences from baseline conditions $(\#, \# \#, \# \# \#)$ and particular control vehicle measurements $(*, * *, * * *)$ for each treated group are respectively indicating $p<0.0 \mathrm{I}, p<0.00 \mathrm{I}$, and $p<0.000$ I. 

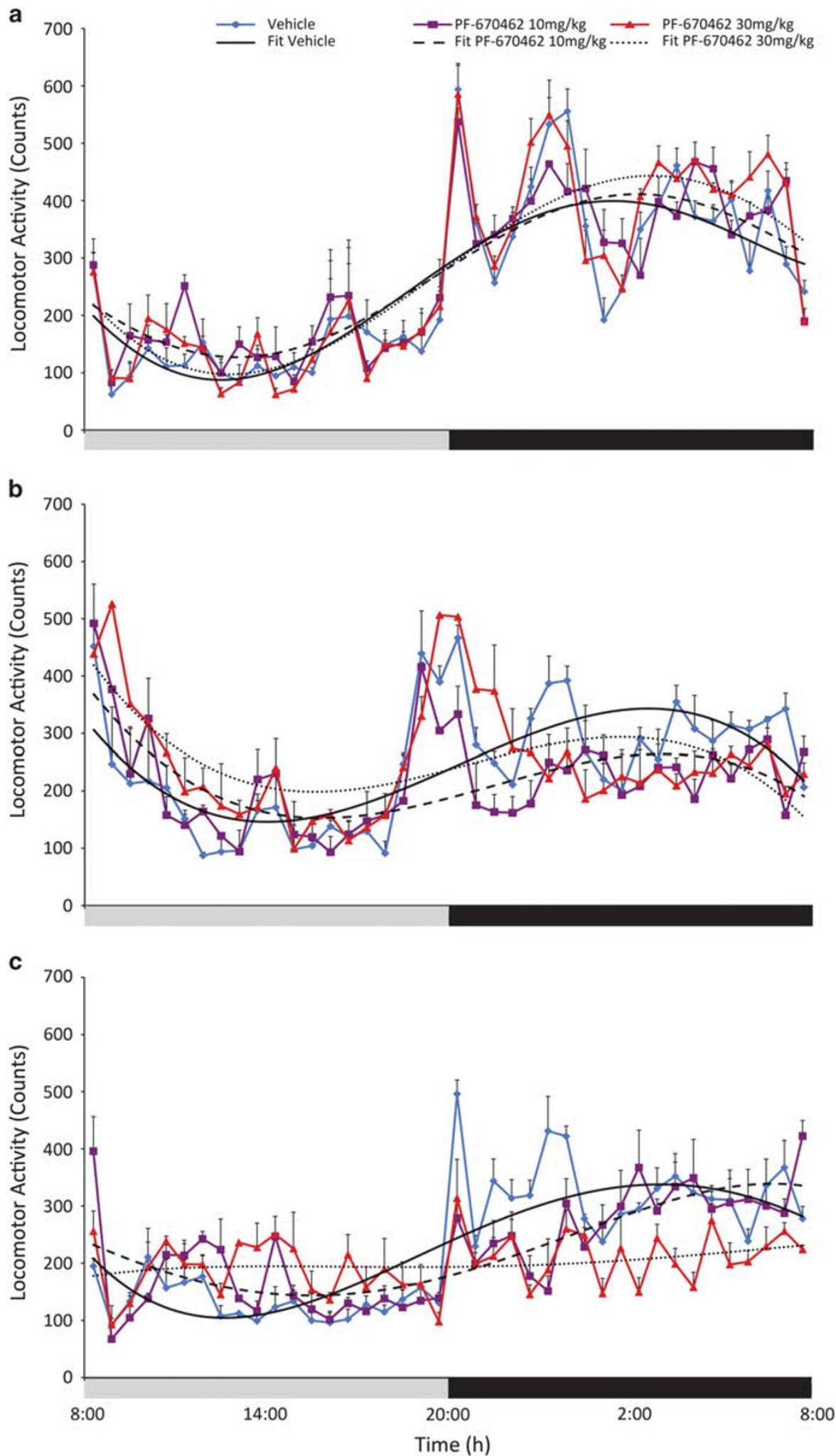

Figure 3 Curve fittings of daily rhythm locomotor activity patterns under baseline conditions (a), during (b), and after (c) treatment administration in vehicle- and 10 and 30 mg/kg PF-670462-treated animal groups. Group-averaged locomotor activity taken every 30 min over a light/dark cycle for the last 6 baseline days (a), the 2 first days of alcohol re-exposure (b), and the 4 following days (c). Curve fits represent the best equation fit of our data. Data are presented as means + SEM.

As compared with vehicle treatment, the $30 \mathrm{mg} / \mathrm{kg}$ PF670462 treatment induced a significant $12.5 \mathrm{~h}$ phase shift in the rhythmic pattern of saccharin intake without affecting the mean levels or amplitude of intake (Figure 5b, Table 1c, and Supplementary Table S4 and S5). During posttreatment days, significantly lower mean levels of saccharin intake 


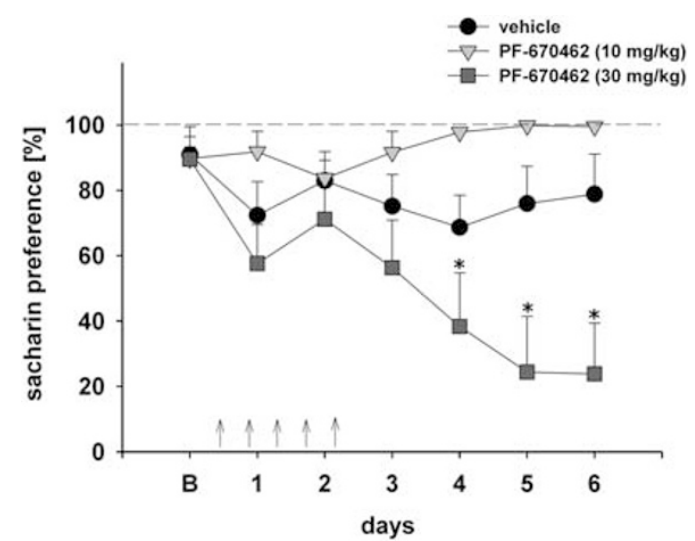

Figure 4 Daily saccharin preference in vehicle $(n=8), 10 \mathrm{mg} / \mathrm{kg}$ PF$670462(n=7)$, and $30 \mathrm{mg} / \mathrm{kg}$ PF-670462 $(n=5)$ groups. Group-averaged daily preference taken for a period of $24 \mathrm{~h}$ averaged for the last 6 baseline days, the 2 last days of the treatment, and 4 last following days. The treatment differentially affected preference for the saccharin solution $\left(F_{\text {Day } \times \text { Group }}(I 2, I 02)=4.7, p<0.000 I\right)$. During the posttreatment phase, $30 \mathrm{mg} / \mathrm{kg}$ PF-670462-treated rats showed decreased preference for saccharin as compared with vehicle-treated rats, as revealed by the significant post-hoc tests $(p<0.05)$ for the days after treatment. Arrows indicate the administration of either vehicle or PF-670462. Data are presented as means + SEM. *Significant differences from the control vehicle group, $p<0.05$.

were also observed in $30 \mathrm{mg} / \mathrm{kg}$ PF-670462-treated rats (Figure 5c and Table 1c). In contrast, $10 \mathrm{mg} / \mathrm{kg}$ PF-670462treated rats did not show a significant difference in saccharin consumption as compared with vehicle-treated rats (Figure $5 c$ and Table $1 c$ ).

As shown in Supplementary Figure S8, the amount of food consumed during the treatment was differentially affected by the treatment $\left(\mathrm{F}_{\text {Day } \times \operatorname{Group}}(12,102)=13.2\right.$, $p<0.0001)$. Although $30 \mathrm{mg} / \mathrm{kg}$ PF-670462 administration significantly decreased food intake, no significant changes were observed upon $10 \mathrm{mg} / \mathrm{kg}$ PF-670462 administration. In contrast, PF-670462 did not significantly affect body weight $(\mathrm{F}(2,17)=0.26, p=0.77)$ at either dose $(0.4 \pm 0.2 \%$, $0.5 \pm 0.4 \%$, and $0.1 \pm 0.6 \%$ for the vehicle- and 10 -, and $30 \mathrm{mg} / \mathrm{kg}$ PF-670462-treated rats, respectively).

\section{DISCUSSION}

Our results suggest that in long-term alcohol-drinking rats, inhibition of $\mathrm{CK} 1 \varepsilon / \delta$ activity prevents relapse-like drinking. This effect was maintained for several days following the treatment period in a dose-dependent manner. Other physiological functions that are under circadian control, such as locomotor activity and water intake, were also influenced by $\mathrm{CK} 1 \varepsilon / \delta$ inhibition. During the posttreatment interval, the highest dose of PF-670462 (30 mg/kg) blunted the diurnal rhythm of these parameters. This observation was confirmed in the saccharin experiment, in which the highest dose of PF-670462 reversed the rhythm of intake of saccharin (without affecting the total intake) during the administration period, and disturbed the diurnal rhythm of saccharin intake and reduced preference to saccharin in the posttreatment interval. This inhibitory posttreatment effect was not seen with the lower dose of the compound
(10 mg/kg PF-670462). In contrast, during the alcohol deprivation effect, alcohol-drinking patterns and intake were strongly influenced by both doses of PF-670462. In conclusion, $\mathrm{CK} 1 \varepsilon / \delta$ inhibition dose-dependently reduced relapse-like drinking behavior. Physiological effects under circadian control, such as locomotion and water intake, were also influenced by $\mathrm{CK} 1 \varepsilon / \delta$ inhibition, which interferes with the master-clock machinery. These effects were more pronounced in the posttreatment phase and parallel our observations with saccharin intake. Hence, our data show that $\mathrm{CK} 1 \varepsilon / \delta$ inhibition reduces alcohol drinking during a relapse condition, an effect likely distinct from its modulation of physiological functions.

The relationship between circadian rhythms/clock genes and mental illnesses such as depression and drug addiction has been emphasized for the last decade (Perreau-Lenz et al, 2007; Rosenwasser, 2010). Under alcohol withdrawal, for instance, alcoholic patients show a circadian rhythm impairment of several physiological functions, such as sleep (Imatoh et al, 1986) and melatonin release (Danel et al, 2009). In rodents, both long-term alcohol intake (Seggio et al, 2009; Rosenwasser et al, 2005b) and alcohol withdrawal (Rosenwasser et al, 2005a; Ruby et al, 2009) have been shown to affect circadian rhythms of locomotor activity. During baseline drinking, our regression analysis revealed, however, a clear daily pattern of drinking and locomotor activity following long-term voluntary alcohol consumption. As opposed to the circadian studies mentioned above, our experiments were conducted under $12 \mathrm{~h}: 12 \mathrm{~h}$ light/dark conditions, which might mask any potential disturbance in circadian activity.

During postabstinence days, the diurnal rhythm of alcohol drinking was impaired in vehicle-treated rats, as characterized by a dampened rhythmic pattern with high intake levels and a shift of alcohol consumption toward light phase, largely because of a particularly high intake of the $20 \%$ solution during the light phase. These data are in agreement with previous data suggesting that compulsive drinking behavior occurring in long-term alcohol-experienced rats following a deprivation period circumvents circadian drinking activity (Spanagel and Hölter, 1999; Vengeliene et al, 2009; Vengeliene et al, 2012).

In the $\mathrm{CK} 1 \varepsilon / \delta$ inhibitor-treated rats, the daily drinking rhythm of alcohol intake was altered not only during the administration of the treatment, but also during subsequent days, indicating a long-lasting effect. In addition, the administration of PF-670462 differentially altered the diurnal patterns of locomotor activity and alcohol intake. As shown in Table $1 \mathrm{a}$ and $\mathrm{b}$, during the treatment period the administration of the higher dose of PF-670462 strongly affected the period of the alcohol intake rhythm $(48 \mathrm{~h})$ without significantly affecting the period of the locomotor activity rhythm $(20.4 \mathrm{~h})$. During posttreatment days, $30 \mathrm{mg} /$ kg PF-670462-treated rats showed a reversed, moderate, and constant locomotor activity throughout the light/dark cycle and a blunted rhythm of alcohol intake with a $6.6 \mathrm{~h}$ phase shift. These data may indicate desynchronization of both rhythmic functions. The effects of the $\mathrm{CK} 1 \varepsilon / \delta$ inhibitor treatment on locomotor activity rhythms observed in the present study are consistent with previous studies (Etchegaray et al, 2009, 2010; Meng et al, 2010; Walton et al, 2009). The lower dose of PF-670462 (10 mg/kg) induced a 


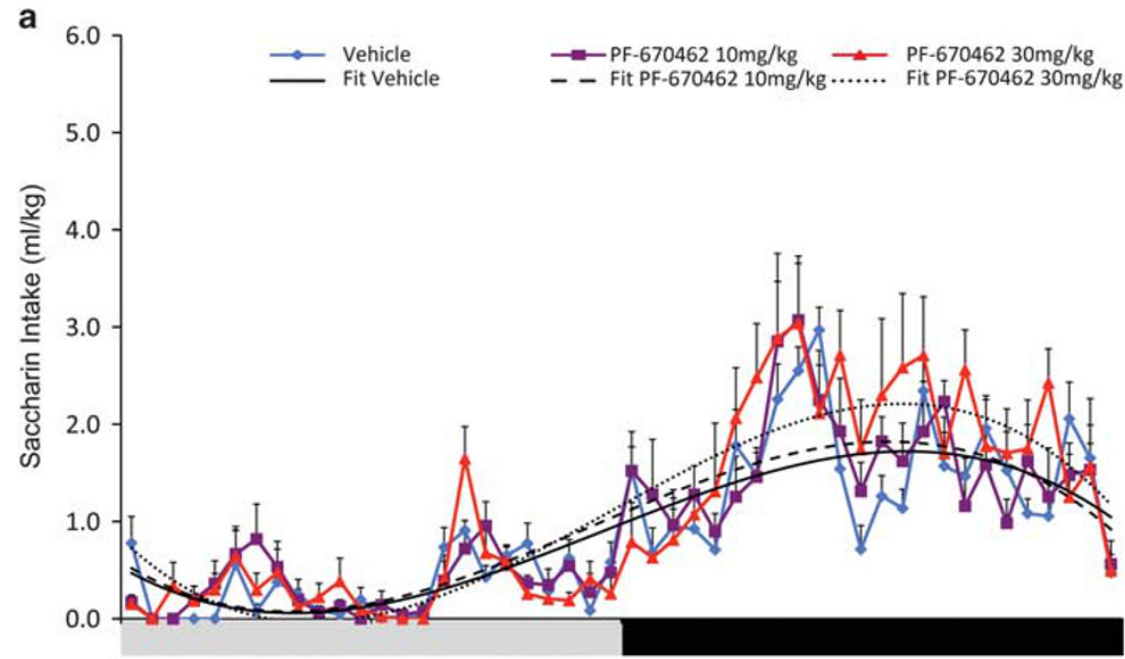

b

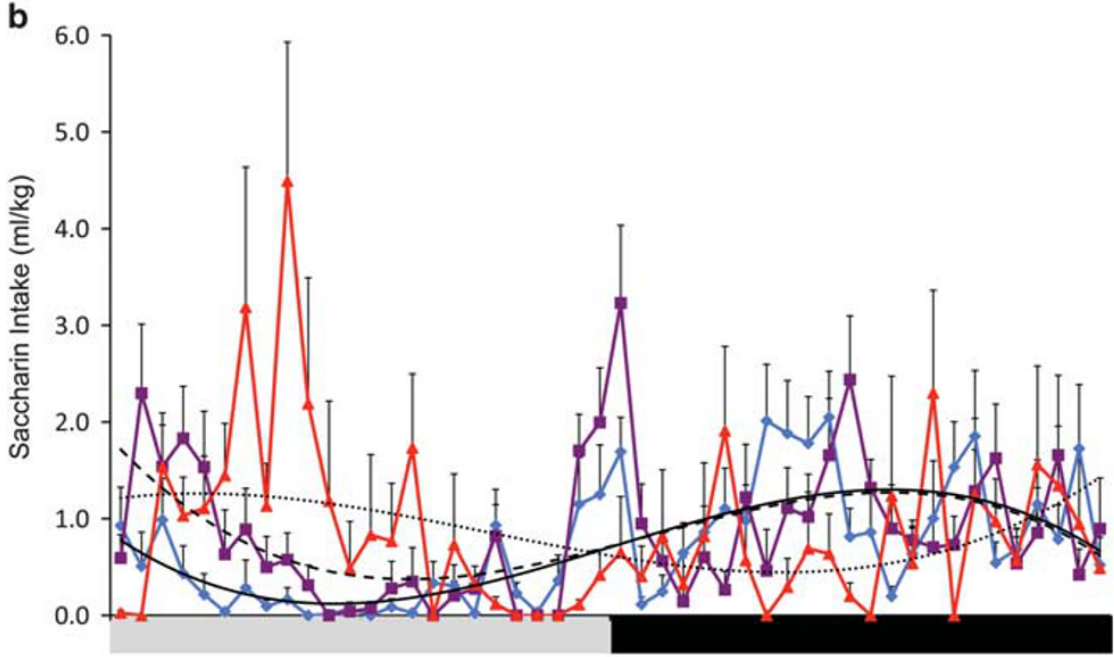

C

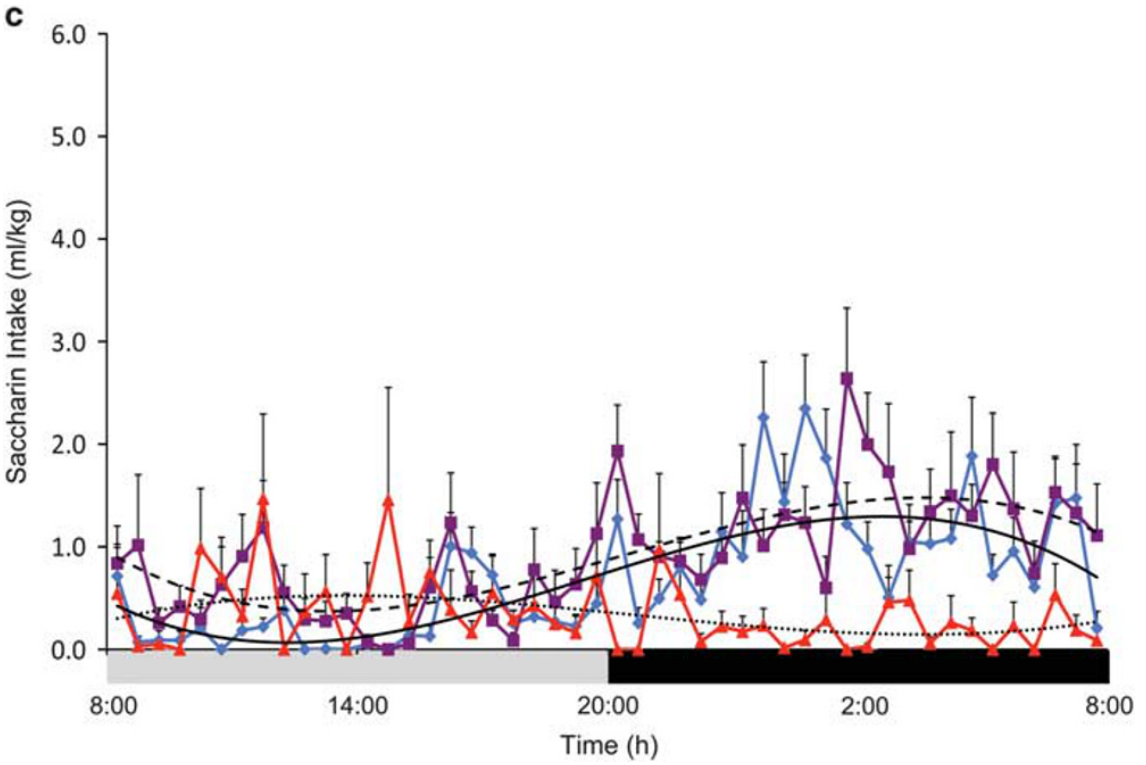

Figure 5 Curve fittings of daily rhythm saccharin intake patterns under baseline conditions (a), during (b), and after (c) treatment administration in vehicle, 10 mg/kg PF-670462, and 30 mg/kg PF-670462 groups. Group-averaged total saccharin intake taken every 30 min over a light/dark cycle for the last 6 baseline days (a), the 2 last days of the treatment (b), and the 4 following days (c). A clear daily rhythm in saccharin intake was measured during baseline conditions, with most intakes occurring during the night. Upon $30 \mathrm{mg} / \mathrm{kg}$ PF-670462 treatment, the rhythmic pattern of saccharin intake shifted toward daytime as compared with vehicle-treated rats. Curve fits represent the best equation fit of our data. Data are presented as means + SEM. 
much lower disturbance of diurnal locomotor activity than the higher dose but still had a strong and long-lasting effect on the reduction of the alcohol deprivation effect.

The present results implicate $\mathrm{CK} 1 \varepsilon / \delta$ activity in the pathways leading to alcohol relapse-like drinking. Recent evidences indicate a role for CK1 $\varepsilon / \delta$ activity in the stimulant effects of methamphetamine (Bryant et al, 2009), showing that both peripheral and intranucleus accumbens administration of PF-670462 diminished the locomotor stimulant effect induced by methamphetamine. The authors suggested that this effect might be mediated through the phosphorylating action on Dopamine- and cyclic AMP-regulated phosphoprotein-32 (DARPP-32), which has been shown to modulate the effect of various drugs of abuse (Svenningsson et al, 2005). CK1 kinases phosphorylate DARPP-32 (CK1 kinase site Ser130), leading to an inhibition of protein phosphatase I and subsequent phosphorylation of various targets. These posttranslational modifications could lead to synaptic plasticity within the dopaminergic system (Nakano et al, 2010). Interestingly, Ser130A-DARPP-32 mutant mice self-administer more cocaine than their respective wild-type controls (Zhang et al, 2006), suggesting an inhibitory role of CK1 on cocaine self-administration. Regarding alcohol, DARPP-32 has also been shown to play a role in alcohol self-administration and preference (Risinger et al, 2001; see for review Spanagel, 2009). Furthermore, alcohol-induced changes in NMDA receptors observed in D1-receptive neurons are absent in DARPP-32 knockout mutant mice (Maldve et al, 2002). However, direct evidence for an interaction of DARPP-32 and CK $1 \varepsilon / \delta$ inhibition with respect to relapse-like alcohol drinking has yet to be identified.

Per2 ${ }^{\text {Brdm1 }}$ mutant mice, which have increased levels of glutamate in the nucleus accumbens, show increased alcohol consumption when compared with their control littermates, suggesting that PER2 may inhibit alcohol selfadministration through its action on the glutamatergic system (Spanagel et al, 2005). The inhibition of CK1 $\delta$ activity increases the nuclear presence of PER2 protein (Meng et al, 2008). Thus, upon CK1 $/ \delta$ inhibition, an increased stabilization of the PER2 protein may lead to an increase of this inhibitory effect on alcohol self-administration. Considering the inhibitory role of PER2 in excessive alcohol consumption and the involvement of $\mathrm{CK} 1 \varepsilon / \delta$ in PER2 destabilization, we propose that the effects observed following inhibition of $\mathrm{CK} 1 \varepsilon / \delta$ activity on relapse-like alcohol drinking are mediated via its effect on PER2 activity within the mesocorticolimbic system. Follow-up studies determining the effect of site-specific depletion of kinases Csnkle or Csnk1d on clock gene expression within brain areas involved in reward sensitivity are necessary to provide evidence for these potential mechanisms of action.

In conclusion, our data implicate $\mathrm{CK} 1 \varepsilon / \delta$ in alcohol relapse-like drinking. CK1 $1 \varepsilon / \delta$ inhibition with PF-670462 decreased the alcohol deprivation effect dose-dependently by preventing the compulsive daytime intake of alcohol (especially the $20 \%$ alcohol solution) observed in control rats, and prevented alcohol intake during the days following the treatment. Furthermore, CK1 $1 / \delta$ inhibition influenced the daily rhythms of locomotor activity, water intake, and saccharin intake. Although at a higher dose PF-670462 decreased saccharin preference in the posttreatment phase, impairment of saccharin intake was not seen with the lower dose of the compound. These results suggest a specific action of $\mathrm{CK} 1 \varepsilon / \delta$ inhibition on alcohol intake during treatment. CK1 inhibitors may therefore be promising candidates for further drug treatment development for alcoholism.

\section{ACKNOWLEDGEMENTS}

We thank Sabrina Koch for her technical assistance, and Dr Rick Bernardi for proofreading the manuscript. This work was supported by the Bundesministerium für Bildung und Forschung (NGFN Plus; FKZ: 01GS08152, FKZ: $01 \mathrm{GS} 08155$ see under www.ngfn-alkohol.de and Spanagel et al, 2010; FKZ: 01GS08151) and by a research grant from GlaxoSmithKline (GSK-PSYBIOVR-CT064-2008).

\section{DISCLOSURE}

SP-L, VV, HRN, MAC, and CC have nothing to disclose. EVM-P was a full-time employee at GlaxoSmithKline and is currently employed at Hoffmann-LaRoche. MAC and CC were employed at GlaxoSmithKline and are currently employed at Aptuit. Over the past 3 years, RS has received compensations for research and consultant contracts from Abbott, GSK, Solvay, and Xenoport.

\section{REFERENCES}

Al-Housseini AM, Sivanandam TM, Bradbury EL, Tannenberg RK, Dodd PR, Gu Q (2008). Upregulation of beta-catenin levels in superior frontal cortex of chronic alcoholics. Alcohol Clin Exp Res 32: 1080-1090.

Badura L, Swanson T, Adamowicz W, Adams J, Cianfrogna J, Fisher $\mathrm{K}$ et al (2007). An inhibitor of casein kinase I epsilon induces phase delays in circadian rhythms under free-running and entrained conditions. J Pharmacol Exp Ther 322: 730-738.

Brager AJ, Prosser RA, Glass JD (2011). Circadian and acamprosate modulation of elevated ethanol drinking in mPer2 clock gene mutant mice. Chronobiol Int 28: 664-672.

Brager AJ, Ruby CL, Prosser RA, Glass JD (2010). Chronic ethanol disrupts circadian photic entrainment and daily locomotor activity in the mouse. Alcohol Clin Exp Res 34: 1266-1273.

Bryant CD, Graham ME, Distler MG, Munoz MB, Li D, Vezina P et al (2009). A role for casein kinase 1 epsilon in the locomotor stimulant response to methamphetamine. Psychopharmacology (Berl) 203: 703-711.

Bryant CD, Parker CC, Zhou L, Olker C, Chandrasekaran RY, Wager TT et al (2012). Csnkle is a genetic regulator of sensitivity to psychostimulants and opioids. Neuropsychopharmacology 37: 1026-1035.

Danel T, Cottencin O, Tisserand L, Touitou Y (2009). Inversion of melatonin circadian rhythm in chronic alcoholic patients during withdrawal: preliminary study on seven patients. Alcohol Alcohol 44: 42-45.

Dong L, Bilbao A, Laucht M, Henriksson R, Yakovleva T, Ridinger $M$ et al (2011). Effects of the circadian rhythm gene period 1 (Per1) on psychosocial stress-induced alcohol drinking. Am J Psychiatry 168: 1090-1098.

Eide EJ, Kang H, Crapo S, Gallego M, Virshup DM (2005a). Casein kinase I in the mammalian circadian clock. Methods Enzymol 393: 408-418.

Eide EJ, Woolf MF, Kang H, Woolf P, Hurst W, Camacho F et al (2005b). Control of mammalian circadian rhythm by CKIepsilon-regulated proteasome-mediated PER2 degradation. Mol Cell Biol 25: 2795-2807. 
Etchegaray JP, Machida KK, Noton E, Constance CM, Dallmann R, Di Napoli MN et al (2009). Casein kinase 1 delta regulates the pace of the mammalian circadian clock. Mol Cell Biol 29: 3853-3866.

Etchegaray JP, Yu EA, Indic P, Dallmann R, Weaver DR (2010). Casein kinase 1 delta (CK1delta) regulates period length of the mouse suprachiasmatic circadian clock in vitro. PLoS One 5: e10303.

Falcon E, McClung CA (2009). A role for the circadian genes in drug addiction. Neuropharmacology 56(Suppl 1): 91-96.

Hölter SM, Danysz W, Spanagel R (2000). Novel uncompetitive N-methyl-D-aspartate (NMDA)-receptor antagonist MRZ 2/579 suppresses ethanol intake in long-term ethanol-experienced rats and generalizes to ethanol cue in drug discrimination procedure. J Pharmacol Exp Ther 292: 545-552.

Hölter SM, Spanagel R (1999). Effects of opiate antagonist treatment on the alcohol deprivation effect in long-term ethanolexperienced rats. Psychopharmacology (Berl) 145: 360-369.

Huang MC, Ho CW, Chen CH, Liu SC, Chen CC, Leu SJ (2010). Reduced expression of circadian clock genes in male alcoholic patients. Alcohol Clin Exp Res 34: 1899-1904.

Imatoh N, Nakazawa Y, Ohshima H, Ishibashi M, Yokoyama T (1986). Circadian rhythm of REM sleep of chronic alcoholics during alcohol withdrawal. Drug Alcohol Depend 18: 77-85.

Ko CH, Takahashi JS (2006). Molecular components of the mammalian circadian clock. Hum Mol Genet 15Spec No 2: R271-R277.

Kotaka T, Ujike H, Morita Y, Kishimoto M, Okahisa Y, Inada T et al (2008). Association study between casein kinase 1 epsilon gene and methamphetamine dependence. Ann NY Acad Sci 1139: $43-48$.

Levran O, Londono D, O'Hara K, Nielsen DA, Peles E, Rotrosen J et al (2008). Genetic susceptibility to heroin addiction: a candidate gene association study. Genes Brain Behav 7: 720-729.

Maldve RE, Zhang TA, Ferrani-Kile K, Schreiber SS, Lippmann MJ, Snyder GL et al (2002). DARPP-32 and regulation of the ethanol sensitivity of NMDA receptors in the nucleus accumbens. Nat Neurosci 5: 641-648.

Meng QJ, Logunova L, Maywood ES, Gallego M, Lebiecki J, Brown TM et al (2008). Setting clock speed in mammals: the CK1 epsilon tau mutation in mice accelerates circadian pacemakers by selectively destabilizing PERIOD proteins. Neuron 58: 78-88.

Meng QJ, Maywood ES, Bechtold DA, Lu WQ, Li J, Gibbs JE et al (2010). Entrainment of disrupted circadian behavior through inhibition of casein kinase 1 (CK1) enzymes. Proc Natl Acad Sci USA 107: 15240-15245.

Nakano T, Doi T, Yoshimoto J, Doya K (2010). A kinetic model of dopamine- and calcium-dependent striatal synaptic plasticity. PLoS Comput Biol 6: e1000670.

Perreau-Lenz S, Spanagel R (2008). The effects of drugs of abuse on clock genes. Drug News Perspect 21: 211-217.

Perreau-Lenz S, Zghoul T, de Fonseca FR, Spanagel R, Bilbao A (2009). Circadian regulation of central ethanol sensitivity by the mPer2 gene. Addict Biol 14: 253-259.

Perreau-Lenz S, Zghoul T, Spanagel R (2007). Clock genes running amok. Clock genes and their role in drug addiction and depression. EMBO Rep 8Spec No: S20-S23.

Reischl S, Kramer A (2011). Kinases and phosphatases in the mammalian circadian clock. FEBS Lett 585: 1393-1399.

Risinger FO, Freeman PA, Greengard P, Fienberg AA (2001). Motivational effects of ethanol in DARPP-32 knock-out mice. J Neurosci 21: 340-348.

Rosenwasser AM (2010). Circadian clock genes: non-circadian roles in sleep, addiction, and psychiatric disorders? Neurosci Biobehav Rev 34: 1249-1255.
Rosenwasser AM, Fecteau ME, Logan RW (2005a). Effects of ethanol intake and ethanol withdrawal on free-running circadian activity rhythms in rats. Physiol Behav 84: 537-542.

Rosenwasser AM, Logan RW, Fecteau ME (2005b). Chronic ethanol intake alters circadian period-responses to brief light pulses in rats. Chronobiol Int 22: 227-236.

Ruby CL, Brager AJ, DePaul MA, Prosser RA, Glass JD (2009). Chronic ethanol attenuates circadian photic phase resetting and alters nocturnal activity patterns in the hamster. Am J Physiol Regul Integr Comp Physiol 297: R729-R737.

Salimov RM, Salimova NB (1993). The alcohol-deprivation effect in hybrid mice. Drug Alcohol Depend 32: 187-191.

Seggio JA, Fixaris MC, Reed JD, Logan RW, Rosenwasser AM (2009). Chronic ethanol intake alters circadian phase shifting and free-running period in mice. J Biol Rhythms 24: 304-312.

Sinclair JD, Senter RJ (1968). Development of an alcoholdeprivation effect in rats. Q J Stud Alcohol 29: 863-867.

Spanagel R (2009). Alcoholism: a systems approach from molecular physiology to addictive behavior. Physiol Rev 89: 649-705.

Spanagel R, Bartsch D, Brors B, Dahmen N, Deussing J, Eils R et al (2010). An integrated genome research network for studying the genetics of alcohol addiction. Addict Biol 15: 369-379.

Spanagel R, Hölter SM (1999). Long-term alcohol self-administration with repeated alcohol deprivation phases: an animal model of alcoholism? Alcohol Alcohol 34: 231-243.

Spanagel R, Kiefer F (2008). Drugs for relapse prevention of alcoholism: ten years of progress. Trends Pharmacol Sci 29: 109-115. Spanagel R, Pendyala G, Abarca C, Zghoul T, Sanchis-Segura C, Magnone MC et al (2005). The clock gene Per2 influences the glutamatergic system and modulates alcohol consumption. Nat Med 11: 35-42.

Svenningsson P, Nairn AC, Greengard P (2005). DARPP-32 mediates the actions of multiple drugs of abuse. AAPS $\mathrm{J}$ 7: E353-E360.

Vengeliene V, Bachteler D, Danysz W, Spanagel R (2005). The role of the NMDA receptor in alcohol relapse: a pharmacological mapping study using the alcohol deprivation effect. Neuropharmacology 48: 822-829.

Vengeliene V, Celerier E, Chaskiel L, Penzo F, Spanagel R (2009). Compulsive alcohol drinking in rodents. Addict Biol 14: 384-396.

Vengeliene V, Heidbreder CA, Spanagel R (2007). The effects of lamotrigine on alcohol seeking and relapse. Neuropharmacology 53: 951-957.

Vengeliene V, Leonardi-Essmann F, Perreau-Lenz S, GebickeHaerter P, Drescher K, Gross G et al (2006). The dopamine D3 receptor plays an essential role in alcohol-seeking and relapse. FASEB J 20: 2223-2233.

Vengeliene V, Leonardi-Essmann F, Sommer WH, Marston HM, Spanagel R (2010). Glycine transporter-1 blockade leads to persistently reduced relapse-like alcohol drinking in rats. Biol Psychiatry 68: 704-711.

Vengeliene V, Noori HR, Spanagel R (2012). The use of a novel drinkometer system for assessing pharmacological treatment effects on alcohol consumption in rats. Alcohol Clin Exp Res (in press).

Walton KM, Fisher K, Rubitski D, Marconi M, Meng QJ, Sladek M et al (2009). Selective inhibition of casein kinase 1 epsilon minimally alters circadian clock period. J Pharmacol Exp Ther 330: 430-439.

Zhang Y, Svenningsson P, Picetti R, Schlussman SD, Nairn AC, Ho A et al (2006). Cocaine self-administration in mice is inversely related to phosphorylation at Thr34 (protein kinase A site) and Ser130 (kinase CK1 site) of DARPP-32. J Neurosci 26: 2645-2651.

Supplementary Information accompanies the paper on the Neuropsychopharmacology website (http://www.nature.com/npp) 